Presented at the 34th JANNAF Combustion Subcommittee Meeting

West Palm Beach, Florida, October, 1997

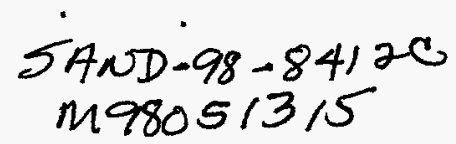

\title{
Coupling Experimental Data and a Prototype Model to Probe the Physical and Chemical Processes of 2,4-Dinitroimidazole Solid-Phase Thermal Decomposition
}

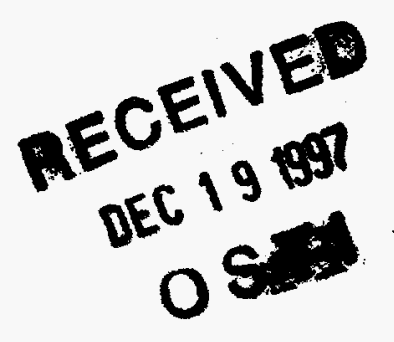

\author{
Richard Behrens and Leanna Minier \\ Combustion Research Facility \\ Sandia National Laboratories \\ Livermore, CA 94551
}

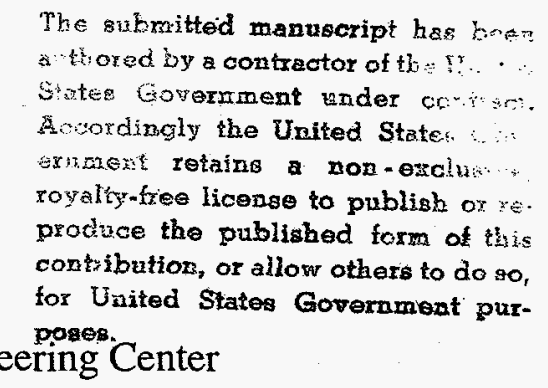
produce the published form of this contubution, or allow others to do so, for United States Government purposes.

Suryanarayana Bulusu ${ }^{\dagger}$

Energetic Materials Division

Dover, NJ 07801-5001

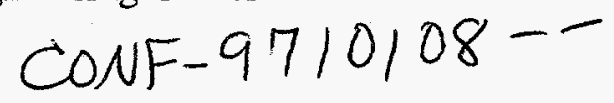

ABSTRACT

The time-dependent, solid-phase thermal decomposition behavior of 2,4-dinitroimidazole (2,4-DNI) has been measured utilizing simultaneous thermogravimetric modulated beam mass spectrometry (STMBMS) methods. The decomposition products consist of gaseous and non-volatile polymeric products. The temporal behavior of the gas formation rates of the identified products indicate that the overall thermal decomposition process is complex. In isothermal experiments with 2,4-DNI in the solid phase, four distinguishing features are observed: 1) elevated rates of gas formation are observed during the early stages of the decomposition, which appear to be correlated to the presence of exogenous water in the sample; 2) this is followed by a period of relatively constant rates of gas formation; 3) next, the rates of gas formation accelerate, characteristic of an autocatalytic reaction; 4) finally, the 2,4-DNI is depleted and gaseous decomposition products continue to evolve at a decreasing rate.

A physicochemical and mathematical model of the decomposition of 2,4-DNI has been developed and applied to the experimental results. The first generation of this model is described in this paper. In this model, decomposition of 2,4-DNI and evolution of gaseous products is controlled by at least six basic processes. These processes include: 1) sublimation and decomposition in the gas phase (small contribution), 2) decomposition in a reactive shell on the surface of the particles, 3) enhancement of the reaction rates and reduction of the 2,4-DNI sticking coefficient due to absorbed exogenous water and impurities in the 2,4-DNI sample, 4) the growth of polymeric reactive nuclei in the reactive shell, 5) adsorption of 2,4-DNI on the surface of the reactive nuclei, followed by reaction of the 2,4-DNI on the surface to release gaseous products and add to the polymer, and 6) transformation of the polymer formed by the initial reaction with 2,4 -DNI to a more thermally stable polymer, releasing gas in the process. The combination of processes four through six characterize the autocatalytic nature of the 2,4-DNI decomposition. Global reaction chemistry is currently used to characterize each of the basic decomposition processes. The development of the model is presented along with examples of the model applied to experiments conducted under a range of different conditions. Differences between the first generation of the model and the experimental data collected under different conditions suggest refinements for the next generation of the model.

\section{INTRODUCTION}

There is an ongoing desire in the propulsion community to develop the capability to predict the response of propulsion systems in abnormal environments, which may be encountered during their deployment, transport or storage. Exposure to elevated temperatures is one of the higher probability abnormal events. This type of situation may arise due to inadvertent exposure to fire or the storage at unusually high temperatures. To characterize the response of propulsion systems to situations in which elevated temperatures are present requires the ability to predict the time to ignition, caused by the elevated temperature, and the violence of the ensuing event, as determined by the likelihood to transition from a steady-state deflagration to an explosion or detonation.

\footnotetext{
* Approved for public release; distribution is unlimited.

‡ Work supported by the Army Research Office, a Memorandum of Understanding between the U.S. Department of Energy and the Office of Munitions and by the U.S. Department of Energy under contract DE-AC04-94AL85000.

t Deceased. 
Empirical models of laboratory scale experiments have been successfully used in 3-dimensional codes to predict both the location and time to ignition. However, a lack of understanding of the processes that control the combustion in a bed of thermally degraded propellant has prevented meaningful predictions of the degree of violence. To overcome this limitation requires developing a better understanding of the combustion processes in thermally degraded propellants. This requires major advances in two areas. First, the morphological and chemical changes in the propellant must be understood as a function of the extent of thermal degradation. Second, the combustive behavior of thermally degraded propellants must be understood. This implies that conductive and convective burning in porous propellants with substantially higher surface areas must be understood.

Our work addresses the first issue. As propellants are slowly heated, the rising temperature leads to changes in the morphology of the propellant, as the various ingredients undergo phase changes. Accompanying these changes in morphology are chemical changes caused by the thermal decomposition processes in the various ingredients. The accumulative effect of morphological and chemical changes in the propellant will determine the state of the propellant at any given time. The challenge is to understand the mechanisms that lead to both the morphological an chemical changes, and to quantitatively predict the extent of these changes as a function of time and temperature. This is a difficult problem, but one that may now be addressed with new experimental and computational capabilities.

This paper addresses one specific aspect of the problem, the thermal decomposition processes of energetic ingredients used in propellants. More specifically, this paper addresses the issues associated with both morphological and chemical changes that occur in energetic materials as they are heated slowly, below their ignition point. In this regime, reactions in the condensed phase (solid phase of the reactant or solid/solution phase of reactant and decomposition products) dominate the thermal decomposition processes. Typical thermal analysis techniques such as differential scanning calorimetry (DSC), thermogravimetric analysis (TGA), or one-dimensional time to explosion (ODTX) methods give information on heat generation, mass loss, and time to ignition, respectively. While this information is useful for determining the temperature range in which significant events occur in the materials, and possibly determining the temperature dependence of the overall process, they do not provide information on the physical and chemical processes that underlie the overall process. Thus, one is not able to extract information from this data that will allow one to predict the state of the material as a function of time and temperature.

In our work over the last twelve years, we have conducted experiments on various energetic materials with the goal of understanding the physicochemical processes that control their decomposition behavior. One universal conclusion of this work is that there is always more than one process that contributes to control the rate of decomposition, and that these processes are almost always coupled with each other. This implies that the application of a unimolecular decomposition model, in which the weakest bond in the molecule determines the rate of decomposition, provides an inadequate framework with which to characterize the decomposition processes. We have also found that profound changes in the morphological features of the material often accompany the chemical changes.

In our past work on the decomposition of energetic materials, we have uncovered many of the underlying processes that control their rates of decomposition. We have published work on the decomposition of cyclic nitramines, (HMX, ${ }^{1-3} \mathrm{RDX},{ }^{3-5}$ the mononitroso analogue of $\mathrm{RDX},{ }^{6} \mathrm{TNAZ}^{7}$ TNCHP and $\mathrm{K} 6^{8}$ ), several azoles (14DNI, ${ }^{9} 24 \mathrm{DNI},{ }^{10}$ and $\mathrm{NTO}^{11}$ ), and ammonium perchlorate (AP) and AP-based propellants. ${ }^{12}$ In addition to providing new insight into the underlying decomposition processes, we have obtained extensive quantitative data on the rates of formation of the gaseous products formed during the decomposition processes. We continue with new experiments to add to our knowledge of these materials.

Currently, we are extending our methods to new levels, by developing procedures to create mathematical models of the physicochemical processes that occur during the thermal decomposition of energetic materials from the data measured in our experiments. The ultimate goal of this effort is to create mathematical models of the decomposition processes that can account for the following types of changes in an energetic material as it decomposes:

1. Identities and rates of formation of the gaseous and condensed-phase products.

2. Changes in particle morphology and surface area of particles in propellant.

3. Changes in porosity, hardness, strength of the propellant. 


\section{DISCLAIMER}

This report was prepared as an account of work sponsored by an agency of the United States Government. Neither the United States Government nor any agency thereof, nor any of their employees, makes any warranty, express or implied, or assumes any legal liability or responsibility for the accuracy, completeness, or usefulness of any information, apparatus, product, or process disclosed, or represents that its use would not infringe privately owned rights. Reference herein to any specific commercial product, process, or service by trade name, trademark, manufacturer, or otherwise does not necessarily constitute or imply its endorsement, recommendation, or favoring by the United States Government or any agency thereof. The views and opinions of authors expressed herein do not necessarily state or reflect those of the United States Government or any agency thereof. 
DISCLAIVIER

Portions of this document may be illegible in electronic irogge products. Insges are produced from the best available original documenter 
Presented at the 34th JANNAF Combustion Subcommittee Meeting

West Palm Beach, Florida, October, 1997

4. Energy content of remaining material

-- in reactant

-- in gaseous decomposition products.

This paper illustrates our efforts to develop procedures for creating mathematical models of the physicochemical processes that occur during the slow decomposition of energetic materials. Our desire is to create models of the thermal decomposition of HMX, RDX and AP-based composite propellants, but we begin here with development of a model for 2,4-DNI, which we believe is an easier starting point (although not that easy as we believe the reader will recognize by the conclusion of the paper).

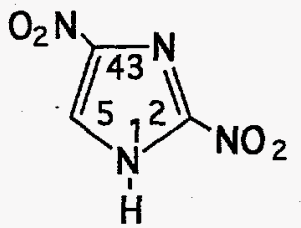

I 2,4-DNI

The 2,4-dinitroimidazole (2,4-DNI; $\mathbf{I})$, is a C-nitro heterocycle compound, that has been shown 13 to be a low cost, thermally stable, and impact insensitive energetic material. Under shock loading, it has been shown to be less shock sensitive than other conventional bonded explosives, with the exception of TATB-based materials. ${ }^{14}$ It also significantly outperforms TNT. Several features of the 2,4-DNI decomposition make it attractive to model. We have thoroughly studied its thermal decomposition utilizing STMBMS methods. The data show that 2,4-DNI has several interesting decomposition features. These include: competition between formation of polymeric and gaseous products, creation of new reaction pathways through nucleation processes, and the creation of a decomposition product that acts as an autocatalyst. Similar processes occur in other energetic compounds we are studying. Therefore, the model for 2,4-DNI thermal decomposition can be modified, expanded and applied to other compounds with similar behaviors.

\section{EXPERIMENTAL}

\section{INSTRUMENTATION AND METHODS}

The design and operation of the STMBMS apparatus and the basic data analysis procedures have been described previously. ${ }^{15-17}$ The data from this instrument provides the identities and temporal dependence of the gas formation rates of the thermal decomposition products formed as a sample decomposes. The exhaust rate of gases from the reaction cell is controlled by changing the diameter of the orifice in the reaction cell, which allows gases to escape from the cell into a vacuum. This feature is used for altering the reaction conditions in two ways. First, as the diameter of the orifice is decreased, the pressure of the gaseous decomposition products in the cell increases. For compounds in which reactions between the gaseous decomposition products and the reactant occur, this allows the contribution of this pathway to be identified and separated from other competing pathways. Second, as the diameter of the orifice is increased, the fraction of the sample that sublimes, without reacting, increases. For studying reactions in the solid phase this allows one to vary the fraction of nearest neighbors in the sample that decompose. Thus, it is possible to sort out reactions in the solid phase that depend on interactions with nearest neighbors from those that do not. The use of these features will be illustrated with the results on 2,4-DNI and the accompanying model of its decomposition.

Several changes in the experimental methods have been made since earlier publications. First, the cap in the reaction cell is now sealed using vacuum grease and a viton o-ring between the taper plug and the gold foil pinhole orifice. The results from decomposition experiments presented in this paper utilize a gold foil with a $25 \mu \mathrm{m}$ - and $50 \mu \mathrm{m}$-diameter orifices. Second, the data presented in this paper for the rate of generation of gaseous products is the rate of their exhaust from the reaction cell, as compared to the rate of their formation within the cell as was presented in our previous papers. This change allows direct comparison between the experimental results and the model.

\section{MATERIALS}

Unlabeled 2,4-DNI (98 $\pm 1 \%$ purity) samples were obtained from Dr. Phil Pagoria at LLNL and used as received. The major impurities in the 2,4-DNI samples are water and the synthetic starting material, 4 nitroimidazole (4-NI). 


\section{RESULTS AND DISCUSSION}

\section{CHARACTERISTICS OF SOLID-PHASE THERMAL DECOMPOSITION}

Our experiments show that neat 2,4-DNI undergoes substantial thermal decomposition in the solid phase between $200^{\circ} \mathrm{C}$ and $255^{\circ} \mathrm{C}$. The identities of the pyrolysis products in the temperature range studied, have been reported previously. ${ }^{18}$ Between $200^{\circ} \mathrm{C}$ and $255^{\circ} \mathrm{C}, 2,4$ DNI undergoes simultaneous sublimation and decomposition. The major products consist of low-molecular weight gases ( $\mathrm{NO}, \mathrm{CO}_{2}, \mathrm{H}_{2} \mathrm{O}, \mathrm{HNCO}, \mathrm{CO}, \mathrm{N}_{2}$ and $\mathrm{HCN}$ ), and a nonvolatile, polymeric residue. The temporal behaviors of the product gas formation rates (GFRs) are similar for the entire temperature range studied. The results from a typical experiment are represented by the GFR data of the major gaseous products formed at $235^{\circ} \mathrm{C}$, shown in Figure 1. There are several interesting features of the temporal behaviors of the GFRs of the various products.

1. As the sample approaches its isothermal temperature, water appears early and is correlated with an increase in the vaporization rate of 2,4-DNI and an increase in the GFRs of the decomposition products.

2. After these initial GFRs decrease, there is a period of relatively constant GFRs for all major products.

3. Following the period of relatively constant GFRs, there is an accelerating rate of increase in the GFRs, typical of an autocatalytic process. The rate of increase continues to accelerate until the 2,4-DNI is depleted at approximately 38000 seconds.

4. Decomposition products continue to evolve after the 2,4-DNI is depleted. At the completion of the experiment, approximately $40 \%$ of the 2,4-DNI that has decomposed (not sublimed) remains as a nonvolatile polymeric residue.

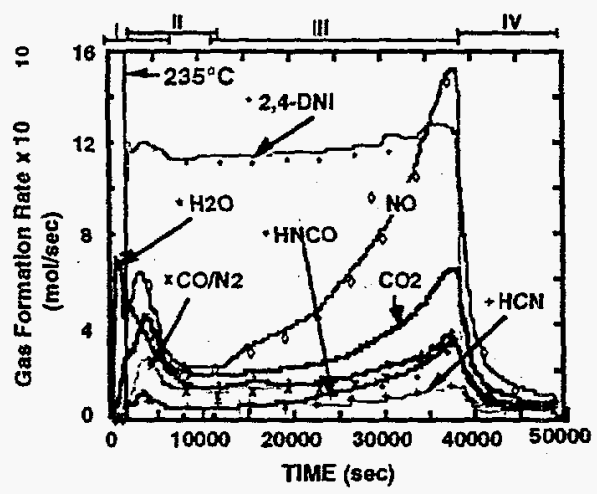

Figure 1. Gas formation rates of products from the isothermal decomposition of $10.3 \mathrm{mg}$ of $2,4-\mathrm{DNI}$ at $235^{\circ} \mathrm{C}$ in a $0.193 \mathrm{cc}$ reaction cell with a $25 \mu$-diameter exit orifice. Isothermal $235^{\circ} \mathrm{C}$ is obtained at $\sim 2300$ seconds, and maintained throughout the remainder of the experiment.

The processes involved in each stage of the decomposition are better clarified by a series of three experiments, each designed to highlight the various stages of the decomposition. In the first experiment, 2,4-DNI $(\sim 10 \mathrm{mg})$ is heated and maintained at $200^{\circ} \mathrm{C}$ for four hours. This experiment is designed to eliminate adsorbed $\mathrm{H}_{2} \mathrm{O}$ and contaminants that may be contributing to the early decomposition stage. In the second experiment, the contents remaining in the reaction cell from the first experiment are thermally decomposed at $235^{\circ} \mathrm{C}$ to completion (2,4-DNI is no longer present). The second experiment is designed to observe if the early decomposition is eliminated by the previous experiment, and to observe the decomposition of neat 2,4-DNI. In the third experiment, the residue formed in the second experiment is cooled to room temperature, mixed with additional 2,4-DNI $(10 \mathrm{mg})$, and decomposed to completion at $235^{\circ} \mathrm{C}$. The third experiment is designed to observe if the residue is acting as an autocatalyst in the decomposition reaction. The resulting product GFRs of the three experiments are shown in Figures $2 \mathrm{a}-\mathrm{c}$. 

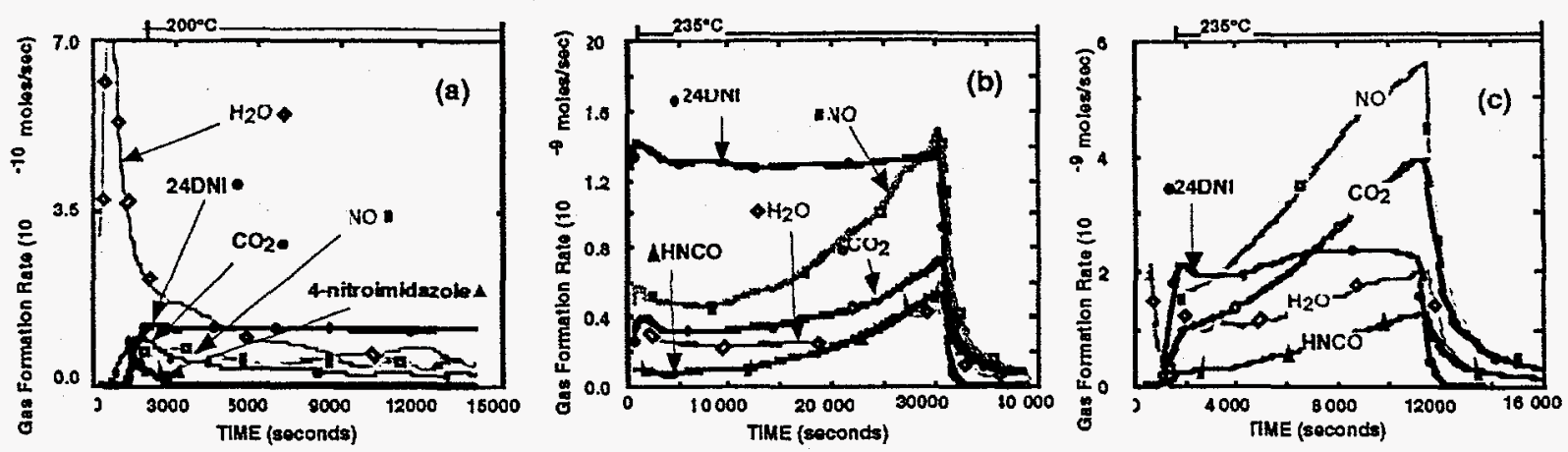

Figure 2. Gas formation rates of the products from three experiments; (a) decomposition of $\sim 10 \mathrm{mg}$ of 2,4-DNI at $200^{\circ} \mathrm{C}$, (b) decomposition at $235^{\circ} \mathrm{C}$ of the 2,4-DNI remaining from the previous experiment and (c) decomposition at $235^{\circ} \mathrm{C}$ of $10 \mathrm{mg}$ of fresh 2,4-DNI that is mixed with the residue from experiment (b).

Early decomposition stage. The dominant process during this stage is desorption of the water from the surface layers of the 2,4-DNI particles as 2,4-DNI sublimes, and the loss of impurities remaining from the synthesis, such as 4-NI. The GFRs of the species that evolve as 2,4-DNI is taken and held at $200^{\circ} \mathrm{C}$ are shown in Figure $2 \mathrm{a}$. There is an onset of decomposition that occurs near the time when 2,4-DNI begins to sublime. Water is the most abundant evolving gas, obtaining a maximum GFR as $200^{\circ} \mathrm{C}$ is approached, and then decaying with time. Studies with deuterium labeled 2,4DNI- $\mathrm{D}_{2}$ have shown that most of the $\mathrm{H}_{2} \mathrm{O}$ that evolves during this time is from an exogenous source and is not a decomposition product. The desorption of water correlates with increased reaction rates during the early decomposition process of 2,4-DNI. Further support for the presence of water altering the early decomposition process is the observed decrease in the extent of the early decomposition when the sample is heated from $200^{\circ} \mathrm{C}$ to the next isothermal temperature of $235^{\circ} \mathrm{C}$ (Fig. 2b). The extent of the increase in the GFRs of the decomposition products during the early decomposition period of mostly-dehydrated 2,4-DNI (Fig.2b), is substantially less than observed during the early decomposition stage of hydrated 2,4-DNI (Fig.1).

Induction and accelerating-rate stages. Two processes dominate the decomposition of 2,4-DNI during the induction and accelerating stages. One process involves either gas-phase reactions within the reaction cell or reactions on the surface of the 2,4-DNI particles. This process forms the observed gaseous products and must lead to the development of the second process. The second process involves reaction between 2,4-DNI and the reactive intermediates formed during the induction stage. As the second process evolves the rate of reaction must increase, suggesting that this process itself accelerates the rate of this process. The temporal behaviors of the GFRs of products formed during each stage is illustrated by the data in Figure $2 \mathrm{~b}$. The induction stage is characterized by the behavior of the product GFRs up to approximately $8000 \mathrm{sec}$, at which point the GFRs start to gradually increase and the accelerating rate stage commences.

Decay stage. This stage is characterized by the evolution of gaseous products formed after the reactant is depleted. The products that evolve during this stage are formed from the decomposition of the secondary nonvolatile products formed during the earlier stages of the decomposition. During this stage of reaction, the processes associated with the direct decomposition of 2,4-DNI have stopped and only products originating from the decomposition of secondary products are observed.

These four stages of the reaction provide the basis for our model of the decomposition of 2,4-DNI.

\section{PROTOTYPE MODEL FOR THE THERMAL DECOMPOSITION OF 2,4-DNI}

A first-generation model to characterize the thermal decomposition processes of 2,4-DNI has recently been developed. The important features of the model are derived from the physical parameters of conducting an experiment in the reaction cell, the temporal behaviors of the GFRs of the gaseous decomposition products, visual observations of the decomposition process, microscopy of the reactant and residual products, and $\mathbb{R}$ spectra of the non-volatile decomposition products. These features are illustrated in Figures 3 and 4. Details of the visual observations, microscopy, and infrared measurements will be included in a future publication. As illustrated in Fig. 3, when the sample is first heated to its isothermal temperature, a quasi-equilibrium is established between the rate of 
vaporization $(\mathrm{kv})$ and rate of condensation $(\mathrm{kc})$ of 2,4-DNI, which essentially maintains 2,4-DNI in the gas phase near its equilibrium vapor pressure. The rate of evolution of 2,4-DNI from the reaction cell is determined by the number density of 2,4-DNI in the reaction cell and the flow characteristics (ke) of gas through the reaction cell orifice. The 2,4-DNI contained in the reaction cell undergoes several different reaction processes (which will be described in more detail below). The gaseous products exit through the reaction cell orifice, their rates also being determined by the flow characteristics of the orifice (ke). As the 2,4-DNI contained in the reaction cell nears depletion, the observed gaseous products evolve solely from a polymeric residue formed during the decomposition.

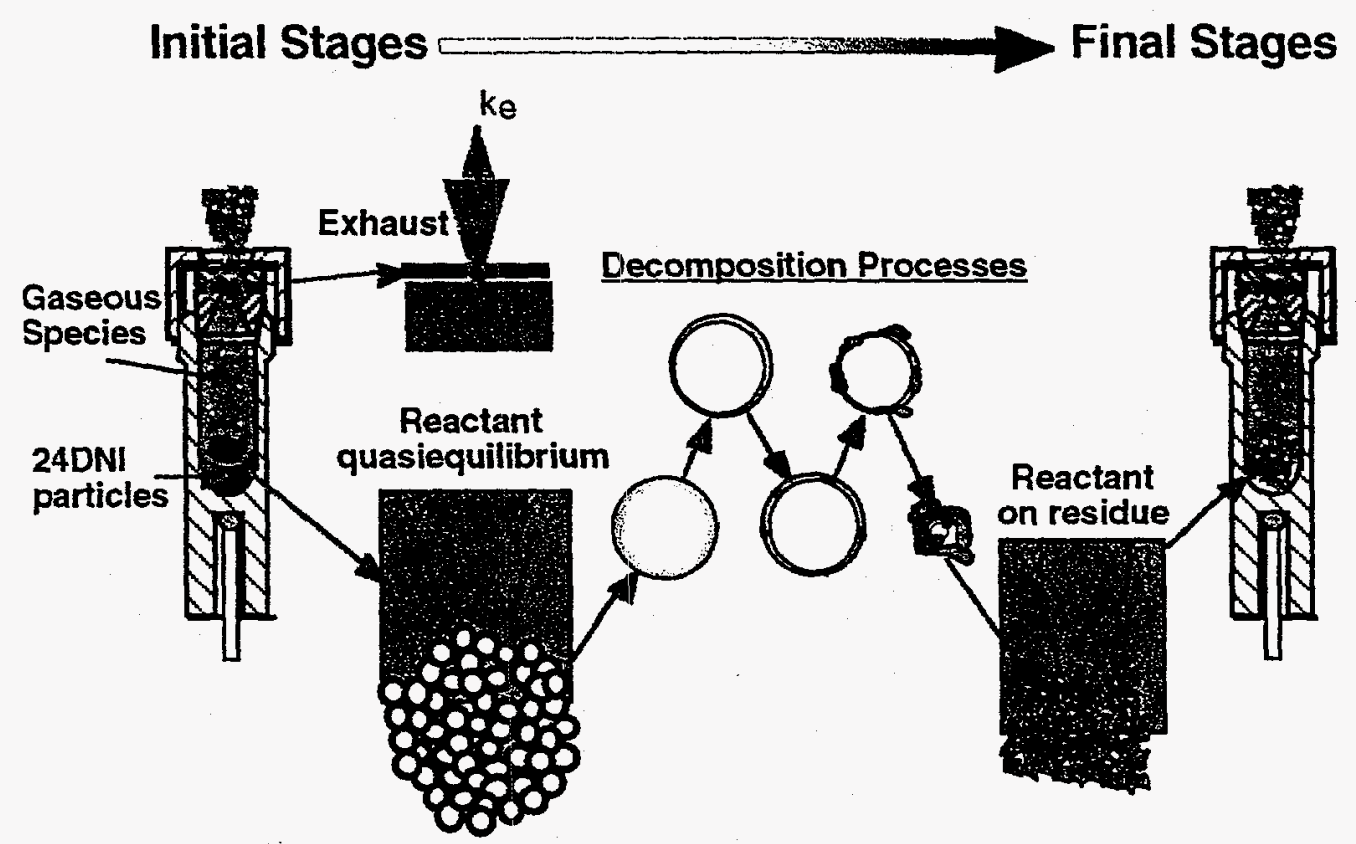

Figure 3. Schematic representation of 2,4-DNI decomposition in a reaction cell.

The general features of the reaction model for the processes that control 2,4-DNI decomposition are illustrated in Figure 4. In this model, 2,4-DNI in the gas phase may decompose within the reaction cell (step 1). The first stages of the decomposition are affected by the presence of water absorbed in the outer layers of the particle (step 2). As the 2,4-DNI begins to decompose, reactions occur in a surface layer on the particle (step 3), and gaseous products evolve. As the 2,4-DNI decomposes in this surface shell, a portion of each molecule remains behind in the shell. The fragments of each decomposed 2,4-DNI molecule remaining in the reactive shell combine to form larger polymeric nuclei (step 4). When these nuclei reach a critical size, they undergo direct reaction with 2,4-DNI. The reaction between the 2,4-DNI and the polymer (A) is then controlled by the transport rate of 2,4-DNI to the polymer surface (A) (step 5) where reaction occurs at the interface between 2,4-DNI and polymer (A) (step 6). Reaction between polymer (A) and 2,4-DNI leads to release of gaseous products and growth of polymer A. As the reactions continue, polymer (A) decomposes, releasing gaseous products and forming a new polymer (B) (step 7). Polymer (B) under the normal course of decomposition can still react with 2,4-DNI, leading to further growth of the polymer. At the model's present state of development, global chemistry is used to represent the various chemical reactions that occur during each of the processes just described. Differences between the rates of gas formation predicted by the model and the measured data will be used to generate a second-generation model of the 2,4-DNI decomposition processes that include more details on the individual chemical reactions involved in each process. Eventually, individual reaction mechanisms will be formulated to characterize each step of the process. 


\section{Reaction in shell on surface}

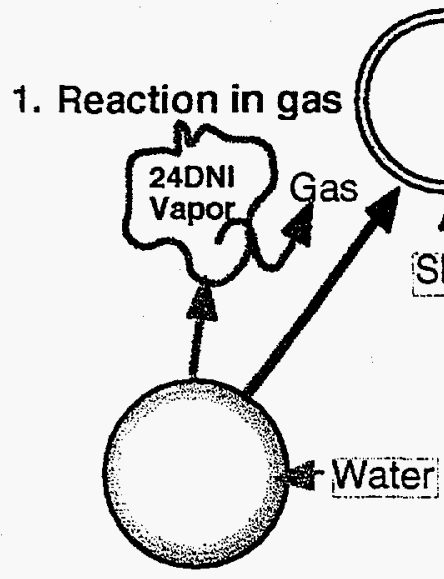

\section{Water absorbed in particles}

5. Transport to polymer surface.

6. Reaction with polymer

Figure 4. Schematic representation of 2,4-DNI decomposition processes in the solid phase.

The global reaction chemistry for the main decomposition processes of 2,4-DNI is captured by fitting the reaction model to our data. The reaction chemistry for the gas phase is characterized by

$$
\begin{aligned}
24 D N I(g) \stackrel{k_{g}}{\rightarrow} & v_{g, N O} \mathrm{NO}+v_{g, C O 2} \mathrm{CO}_{2}+v_{g, H 2 O} \mathrm{H}_{2} \mathrm{O}+v_{g, H N C O} H N C O+ \\
& v_{g, H C N} H C N+v_{g, N 2} N_{2}+v_{g, C O} \mathrm{CO}+v_{g, N 2} N_{2}+v_{8, \text { Pobylg }} \text { PolyIsf }
\end{aligned}
$$

where $\mathrm{k}_{\mathrm{g}}$ is the rate constant for this reaction and $v_{\mathrm{g}, \mathrm{xg}}$ is the global stoichiometric coefficient for species $\mathrm{xxx}$ in this reaction. The reaction in the surface shell is characterized by

$$
\begin{aligned}
24 D N I(s) \stackrel{k_{s}}{\rightarrow} & v_{s, N O} \mathrm{NO}+v_{s, C O 2} \mathrm{CO}_{2}+v_{s, H 2 O} \mathrm{H}_{2} \mathrm{O}+v_{s, H N C O} \text { HNCO }+ \\
& V_{s, H C N} H C N+v_{s, N 2} N_{2}+v_{s, C O} C O+v_{s, N 2} N_{2}+v_{s, P o l y l g} \text { PolyIsf }
\end{aligned}
$$

where $\mathrm{k}_{\mathrm{s}}$ is the rate constant for this reaction and $\mathrm{v}_{\mathrm{s}, \mathrm{x} x \mathrm{x}}$ is the global stoichiometric coefficient for species $\mathrm{xxx}$ in this reaction. This reaction leads to the formation of the species, PolyIsf, that form nucleation centers which react directly with 2,4-DNI after they grow to some critical size. The reaction between the adsorbed 2,4-DNI on the surface of the reactive polymer PolyAs, is characterized by

$$
\begin{aligned}
& 24 D N I(a b)+ \text { PolyAs } \stackrel{k_{r}}{\rightarrow} v_{r, N O} N O+v_{r, C O 2} \mathrm{CO}_{2}+v_{r, H 2 O} \mathrm{H}_{2} \mathrm{O}+v_{r, H N C O} \text { HNCO } \\
&+v_{r, H C N} H C N+v_{r, N 2} N_{2}+v_{r, C O} \mathrm{CO}+v_{r, N 2} N_{2}+\left(1+v_{r, \text { PolyAs }}\right) \text { PolyAs }
\end{aligned}
$$

where $\mathrm{k}_{1}$ is the rate constant for this reaction and $v_{t, x \mathrm{xx}}$ is the global stoichiometric coefficient for species $\mathrm{xxx}$ in this reaction. Note that this reactions leads to the growth of PolyAs. PolyAs then decomposes, releasing gases and forming a second polymeric species, PolyBs. This reaction is characterized by

$$
\begin{aligned}
& \text { PolyAs } \stackrel{k_{\rho 4}}{\rightarrow} v_{p, N O} \mathrm{NO}+v_{p, C O 2} \mathrm{CO}_{2}+v_{p, H 2 O} \mathrm{H}_{2} \mathrm{O}+v_{p, H N C O} \mathrm{HNCO}+ \\
& v_{p, H C N} \mathrm{HCN}+v_{p, N 2} \mathrm{~N}_{2}+v_{p, C O} \mathrm{CO}+v_{p, N 2} N_{2}+v_{p, \text { POlyBs }} \text { PolyBS }
\end{aligned}
$$


where $\mathrm{k}_{\mathrm{pd}}$ is the rate constant for this reaction and $v_{\mathrm{n}, \mathrm{xxx}}$ is the global stoichiometric coefficient for species $\mathrm{xxx}$ in this reaction.

The mathematical model of 2,4-DNI thermal decomposition is described by a set of time-dependent, first order differential equations representing the physical processes and the evolution of gaseous products. For example, the rate of change of 2,4-DNI in the solid phase during the course of a decomposition experiment is described by

$$
\begin{aligned}
\frac{\mathrm{d} 24 \mathrm{DNI}(\mathrm{s})(\mathrm{t})}{\mathrm{dt}}= & \operatorname{asurf} 1(\mathrm{t}) *\left[-\mathrm{ksl}(\mathrm{t}) * \operatorname{xreact}(\mathrm{t})+\operatorname{kcl}(\mathrm{t}) * \operatorname{stick}(\mathrm{t}) * 24 \mathrm{DNI}_{(g)}(\mathrm{t})\right] \\
& -\mathrm{ks} * \text { nshell }(\mathrm{t})
\end{aligned}
$$

where asurf1(t) is the surface area of 2,4-DNI particles, $k s 1(t)$ is the sublimation rate constant, $k c 1(t)$ is the gas kinetic collision rate of 2,4-DNI with the particle surfaces, xreact $(t)$ is the modification of the reactivity of the surface due to water absorbed in the particles, stick $(t)$ is the 2,4-DNI sticking probability on the particle surfaces, $24 D N I(\mathrm{~g})(\mathrm{t})$ is the concentration of 2,4-DNI in the gas phase, $\mathrm{ks}$ is the rate constant for reaction in the surface shell, and nshell $(t)$ is the amount of material in the reactive shells of the particles. An example of a rate expression characterizing the time-dependent behavior of the gaseous product concentrations within the cell is given by the expression for the time-dependent rate of change of NO within the cell,

$$
\begin{aligned}
\frac{\mathrm{dNO}(\mathrm{t})}{\mathrm{dt}}= & \frac{1}{\mathrm{vcell}} *\left[\mathrm{~kg} * \mathrm{vcell}^{*} v_{g, N o} * 24 \mathrm{DNI}_{(\mathrm{g})}(\mathrm{t})+\mathrm{ks}(\mathrm{t}) * v_{\mathrm{s}, \mathrm{NO}} * \mathrm{nshell}(t)+\right. \\
& \left.\mathrm{kr}^{*} v_{\mathrm{r}, \mathrm{NO}} * 24 \mathrm{DNI}_{(\mathrm{ads})}(\mathrm{t})+\mathrm{kpd}^{*} v_{\mathrm{p}, \mathrm{NO}} * \operatorname{PolyA} s(t)\right]-\operatorname{ke} 1(\mathrm{t}) * \mathrm{NO}(\mathrm{t})
\end{aligned}
$$

where vcell is the free volume of the reaction cell, $\mathrm{kg}$ is the rate constant for reaction in the gas phase, $\mathrm{kr}$ is the rate constant for reaction between the polymer and 2,4-DNI adsorbed on the polymer surface, 24DNI(ads)(t), kpd is the rate of decomposition of the polymer, PolyAs to PolyBs, ke1(t) is the constant that characterizes the rate of exhaust from the cell, and $N O(t)$ is the concentration of NO in the cell. The other parameters are defined above.

The rate expression characterizing the time-dependent behavior of water within the cell must also account for the evolution of water that is absorbed in the sample. Thus, the time-dependent concentration of water in the reaction cell is given by

$$
\mathrm{H}_{2} \mathrm{O}_{\mathrm{T}}(\mathrm{t})=\mathrm{H}_{2} \mathrm{O}_{\mathrm{R}}(\mathrm{t})+\mathrm{H}_{2} \mathrm{O}_{\mathrm{A}}(\mathrm{t})
$$

where $\mathrm{H}_{2} \mathrm{O}_{\mathrm{T}}(\mathrm{t})$ is the total concentration of water in the cell, $\mathrm{H}_{2} \mathrm{O}_{\mathrm{R}}(\mathrm{t})$ is the concentration of water originating from the decomposition of 2,4-DNI and $\mathrm{H}_{2} \mathrm{O}_{\mathrm{A}}$ ( $\mathrm{t}$ ) is concentration of water originating from the absorbed water in the particles. The time-dependent rate of change of the concentration of water originating from absorbed water in the particles is given by

$$
\frac{\mathrm{dH}_{2} \mathrm{O}_{\mathrm{A}}(\mathrm{t})}{\mathrm{dt}}=\frac{1}{\text { vcell }}\left(\begin{array}{c}
\mathrm{ks} 1(\mathrm{t}) * \mathrm{xwater}(\mathrm{t}) * \operatorname{asurf}(\mathrm{t})-\operatorname{ke1}(\mathrm{t}) * \mathrm{H}_{2} \mathrm{O}_{\mathrm{A}}(\mathrm{t}) \\
-\operatorname{asurf}(\mathrm{t}) * \mathrm{kcl}(\mathrm{t}) * \mathrm{H}_{2} \mathrm{O}_{\mathrm{A}}(\mathrm{t})
\end{array}\right)
$$

where $x w a t e r(t)$ is the mole fraction of water at the surface of the particle at time $t$ and the other parameters are described above.

The rate of growth of the nuclei in the reactive shell on the 2,4-DNI particles is given by

$$
\frac{\mathrm{d} \text { nuclei }(\mathrm{t})}{\mathrm{dt}}=\operatorname{knuc}^{*} \text { polyIsf }(\mathrm{t})
$$

where knuc is the rate constant for nucleation and PolyIsf is the concentration of the fragments formed from the decomposition of 2,4-DNI in the shell on the surface of the 2,4-DNI particles. When the nuclei reach some critical size they can then undergo reaction directly with 24DNI that is absorbed on their surface.

The rate of growth of polymer, PolyAs, is given by

$$
\frac{\mathrm{dPolyAs}(\mathrm{t})}{\mathrm{dt}}=\mathrm{kr}(\mathrm{t}) * \operatorname{aads}(\mathrm{t})-\mathrm{kpd}(\mathrm{t}) * \operatorname{PolyAs}(\mathrm{t})
$$


Presented at the 34th JANNAF Combustion Subcommittee Meeting

West Palm Beach, Florida, October, 1997

where PolyAs $(\mathrm{t})$ is the monomer unit from each 2,4-DNI molecule that adds to the polymer during the reaction, aads $(t)$ is the amount of 2,4-DNI absorbed on the surface of the polymer, $\operatorname{kr}(t)$ is the rate constant for the reaction of 2,4-DNI absorbed on the surface of the polymer, and $\mathrm{kpd}(\mathrm{t})$ is rate of decomposition of the polymer formed from PolyAs to a different polymer, PolyBs. The stoichiometry of the PolyAs monomer unit is the difference between the stoichiometry of 2,4-DNI and the stoichiometry of the gases lost in the reaction between 2,4-DNI and polymer PolyAs.

The rate of formation of the PolyBs polymer is given by

$$
\frac{\mathrm{dPolyBs}(\mathrm{t})}{\mathrm{dt}}=\operatorname{kpd}(\mathrm{t})^{*} \operatorname{PolyAs}(\mathrm{t})
$$

The stoichiometry of the PolyBs monomer unit is the difference between the stoichiometry of the PolyAs monomer and the stoichiometry of the gases lost as the PolyAs polymer decomposes to the PolyBs polymer.

\section{ILLUSTRATION OF THE MODEL}

Basis Experiment. An illustration of the application of the model to the results from a decomposition experiment conducted at $235^{\circ} \mathrm{C}$ is shown in Figure 5. The set of time-dependent first order differential equations representing the model are solved numerically. The rate constants and stoichiometric coefficients are determined from fits of the model to the measured data. The data in Fig. 5 shows a number of features of the decomposition process. The plots with only species labels show the data (solid lines) and the results of the calculation from the model (dashed line). The plots labeled as "species channels" show the contribution of each decomposition pathway to the rate of formation of each decomposition product. The plot labeled "reaction shell" shows the amount of 2,4-DNI in the reaction shell. For results from all of the calculations involving the reaction shell shown in this paper, the particle size of 2,4-DNI was estimated to be $10 \mu \mathrm{m}$ and the thickness of the reactive shell was assumed to be $10 \mathrm{~nm}$. Thus, a combination of the particle diameter, the thickness of the reaction shell and the rate constant, ks, are coupled parameters in the model. In this case, we held the particle diameter and reaction shell thickness constant and varied ks to fit the data. Figure 5 also shows one plot of the amount of each polymer and another plot of the surface area of the polymer that is available for reaction with 2,4-DNI. For the polymers, polyIsf represents the amount of monomer, formed from reaction in the shell, that is not incorporated into critical size nuclei. Nuclei( $t$ ) represents the amount of polyIsf monomers that have been incorporated into nuclei of a critical size that can react with 2,4-DNI absorbed on their surface. PolymerA represents the PolyAs product and PolymerB represents the PolyBs product.

In this first generation of the model, several assumptions have been made with regard to the polymers. First, the size of the critical size nuclei is an unknown value. In these calculations, we have assumed the nuclei to be spherical and chosen to be a diameter that is some fraction of the 2,4-DNI particle diameter. We have used a value of 1/10th of the 2,4-DNI particle diameter in this paper. Better estimates of this parameter will be made in the future from microscopy measurements. Second, 2,4-DNI is assumed to cover the surface of PolyAs with one monolayer of 2,4-DNI. The gas kinetic collision rate of 2,4-DNI with the surface, under the conditions of these experiments, will easily maintain a coating of 2,4-DNI on the surface of the polymer. Build up of more than one layer of 2,4-DNI on the surface of the polymer probably occurs, but inclusion of this behavior in the model would not add any new features to the process and would increase the complexity of the model. The surface concentration of 2,4-DNI on the polymer is determined by assuming the 2,4-DNI are spherical molecules and estimating the diameter of the individual molecules from the density of 2,4-DNI. Finally, the surface area of the polymer is determined by calculating the amount of decomposed 2,4-DNI that resides in the polymer, calculating the volume occupied by the polymer from estimates of its density, and then distributing the total volume of polymer over the number of critical size nuclei formed up the current point in time. The density of the polymer is assumed to be $\sim 1.4 \mathrm{gm} / \mathrm{cm}^{3}$. This value is based on infrared spectra suggesting the polymer has a polyamide-like functionality and using an average density of several different amino acids. The parameters of the polymer discussed here along with the rate constant $\mathrm{kr}$ form another set of coupled parameters in the model. All of the parameters are kept constant, except for $\mathrm{kr}$, which is varied to fit the data.

The fraction of water absorbed in the particles, $x w a t e r(t)$, is determined from the measurements. The distribution of the water beneath the surface of the particle at time $t=0$ is also determined from the experimental data. In addition, exchange of hydrogen with deuterium on at the labile 2-position of the 2,4-DNI molecule in a deuterium 
labeled 2,4-DNI sample is also used to determine the distribution of the water that has diffused into the 2,4-DNI particles. The details of these measurements will be described in a later publication.

The method used to determine the parameters in the model is as follows:

1. The calculated rate of evolution of 2,4-DNI from the reaction cell is compared to the data. Slight adjustments $(<5 \%)$ are made to the diameter of the orifice to approximately match the initial measured evolution rate of 2,4-DNI.

2. Initial guesses for the stoichiometric coefficients of several products are made.

3. The rate constants, ks, knuc, and $\mathrm{kr}$ are varied to match the temporal behavior of the gas evolution rates, and more importantly, are varied such that the calculated time for depletion of the 2,4-DNI matches the data.

4. The rate constant kpd is varied to match the gas evolution rates after the 2,4-DNI is depleted.

5. The calculated rates of gas evolution for each product are compared to the measured rates. The stoichiometric coefficients are renormalized to obtain the best fit.

6. Steps 3 and 4 are repeated with the new stoichiometric coefficients.

7. The stoichiometric coefficients associated with each process are checked to determine if they appear to be plausible reactions.

For each process, the coupled parameters, the rate constant and stoichiometric factors, can be varied dependently to obtain the same gas evolution rates of the products. However, this variation will require a correlated variation in the other processes to maintain the same length of time for depletion of the sample. Thus, only certain combinations of rate constants and stoichiometric coefficients are allowed. This criteria will be used in future analysis of this data to obtain the most chemically plausible reaction pathways that are consistent with the data.

This data analysis method has been applied to the data set shown in Figure 5. A comparison of the calculated fits with the data shows that the model captures most features of the data. Several interesting features are worth noting. The contribution of the absorbed water $\left(\mathrm{H}_{2} \mathrm{O}\right.$ abs) matches the data quite well. The enhancement in the reaction rates caused by the presence of water is also captured by the model. The origin of some products, such as $\mathrm{H}_{2} \mathrm{O}$ and $\mathrm{CO}_{2}$, is greater from reaction in the shell. Whereas, the origin of other products, such as $\mathrm{HCN}$ and $\mathrm{HNCO}$, is greater from reaction between the polymer and the adsorbed 2,4-DNI. Further examination of the origins of the $\mathrm{HCN}$ and $\mathrm{HNCO}$ show that $\mathrm{HNCO}$ is more likely to originate from the direct reaction of 2,4-DNI with the polymer and less likely to originate from the subsequent decomposition of the polymer while the opposite is true for HCN. The contribution from decomposition in the gas phase is almost zero compared to the other channels. The reason for this situation in the model will become apparent when the results from decomposition in a larger volume reaction cell are discussed below. The final aspect to discuss briefly is the relative amount of the different species associated with nucleation and growth of the polymers. A comparison of the amount of polylsf monomer, that has been incorporated into an active nucleation site (nuclei), to the amount of polyIsf that remains free of active sites (polyIsf), shows that the fraction of polyIsf in the active nuclei during the early stages of the experiment are small. After a small number of nuclei are formed the total amount of polymer available for reaction, the sum of Polymer $\mathrm{A}$ and Polymer B, is formed predominantly by reaction of 2,4-DNI with the polymer. While this nucleation model provides the correct delay for onset of the growth of the polymer, whether or not the nucleation process used here properly characterizes the actual nucleation process in 2,4-DNI will require further experiments. 


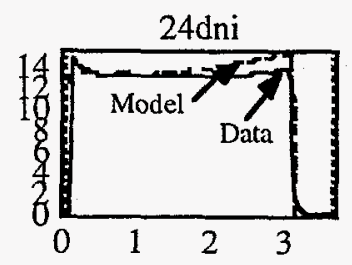

\section{Experimental Parameters:}

Orifice diameter $(\mu \mathrm{m}): 25$.

Isothermal temp (C): 235.6

Reaction cell volume (cm3): 0.199

Sample weight $(\mathrm{mg}): 10.28$

Average particle dia $(\mu \mathrm{m}): \sim 10$. (est.)
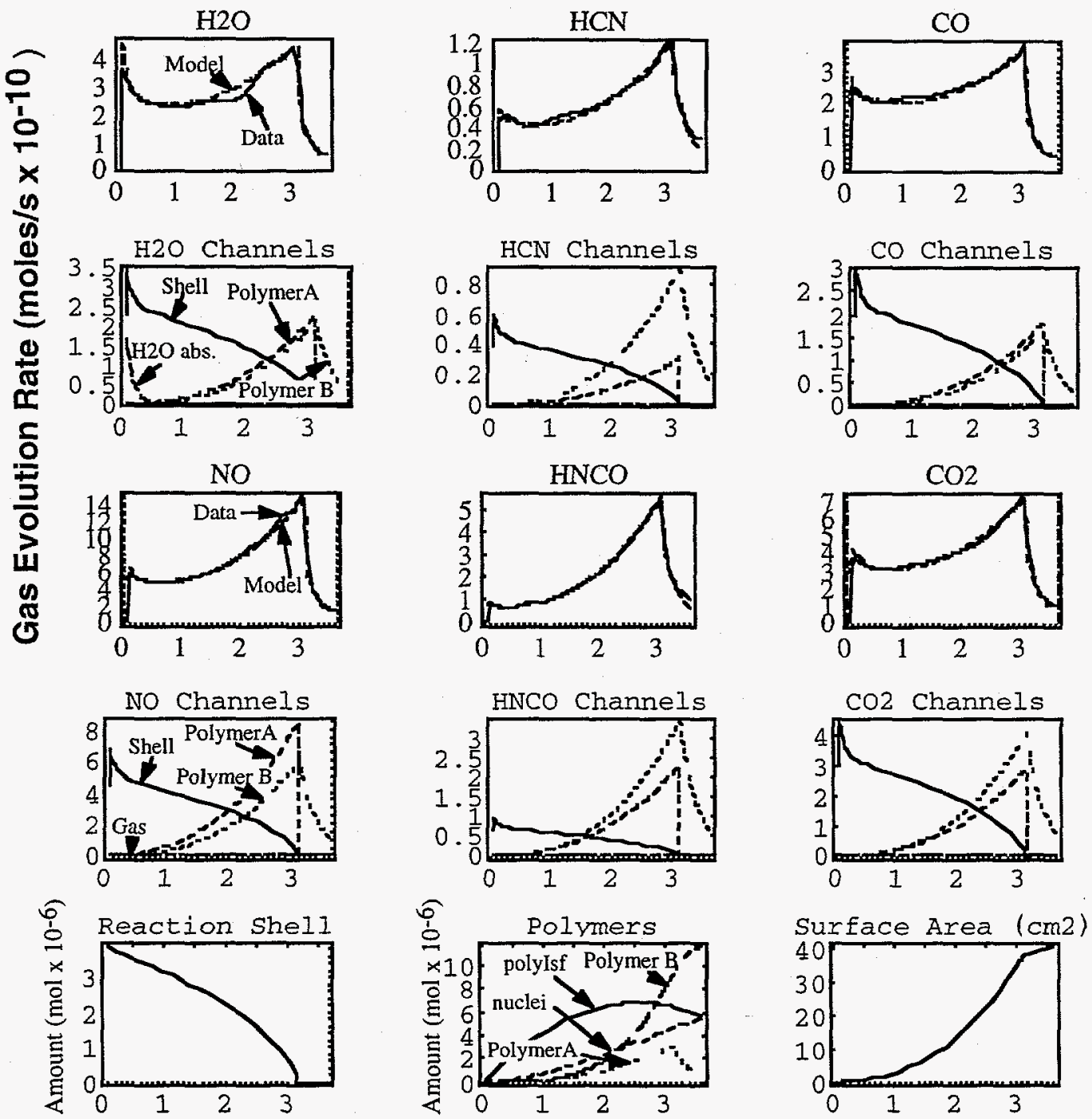

\section{Time $\left(\sec \times 10^{4}\right)$}

Figure 5. The evolution rates of gaseous products from the decomposition of $2,4-\mathrm{DNI}$ at $235^{\circ} \mathrm{C}$ in a reaction cell with a $25 \mu \mathrm{m}$ diameter orifice are shown along with the results from a model of the decomposition process. Plots with only product labels show the measured rate of gas evolution from the reaction cell (solid line) and the resulting fit of the model (dashed line) for each product. Plots of the product channels show the contribution of each channel described in the model to the overall evolution of each decomposition product. The legend for each type of plot is shown in the first plot in each row. 
Catalysis Experiment. The next experiment assessed the catalytic activity of the polymer formed during the decomposition of 2,4-DNI. In this experiment, $10.32 \mathrm{mg}$ of 2,4-DNI was added to the residue remaining from the previous experiment in the manner described above. The data and the results from the model are shown in Fig. 6.

The number of parameters in the rnodel, which were varied for this experiment and the remainder of the experiments described in this paper, were significantly reduced from the first experiment. The reason for this is twofold. First, we wanted to determine how well the parameters from one experiment would fit another. Second, we wanted to identify the variations between the predictions of our model and the data so that we could develop further insights into the processes controlling the decomposition of 2,4-DNI. For the case of the calculation shown in Fig. 6, no parameters in the model were changed from the model calculation used for the experiment shown in Figure 5. The only difference in this model calculation was that the starting values for polyIsf, nuclei, PolyAs and PolyBs were set to their final values from the calculation for the previous experiment.

Comparison of the results of the calculation with the data show many consistencies between the model and the data. First, the rate of decomposition of 2,4-DNI is correctly predicted. Note that the length of time for $\sim 10 \mathrm{mg}$ of 2,4-DNI to decompose in this experiment is $\sim 10,000$ seconds compared to $\sim 31,000$ seconds for the same amount of material in the previous experiment with no added residue. Thus, the model appears to be a good representation of the autocatalytic process. Closer examination of the gas evolution rates show that the calculated rates for $\mathrm{H}_{2} \mathrm{O}$, $\mathrm{HCN}$, NO and $\mathrm{CO}_{2}$ compare quite closely with the data. However, there are larger discrepancies between the calculated and measured gas evolution rates for $\mathrm{CO}$ and $\mathrm{HNCO}$. The origin of these differences will be considered in the future and a better understanding of the process will be incorporated into the next generation of the model.

Gas-phase decomposition. To assess the extent of decomposition of 2,4-DNI in the gas phase, an experiment was carried out in a reaction cell with a volume seven times greater than used in the standard experiments. This increases the fraction of the sample in the gas phase seven-fold. Thus, if the reaction during the early stages of decomposition occur solely in the gas phase, a seven-fold increase in the rate of formation of the decomposition products would be expected. As the results show in Figure 7, for the experiment with the larger volume reaction cell, this is not the case. When the same parameters are used in the model as were used to fit the basis experiment, and the gas-phase rate constant is set to zero, the model provides a good fit to the data (the short dashed line). This indicates that decomposition in the gas phase is not a large contributor to the overall reaction process. This fact led to our development of the reactive shell process as one of the primary decomposition pathways.

To evaluate how decomposition in the gas phase may contribute to the overall rates of evolution of the various products, the rate constant for the gas-phase reaction, $\mathrm{kg}$, was set equal to the rate constant for reaction in the shell, $\mathrm{ks}$, and the calculation was repeated. The results of the calculation are represented by the long dashed line in Figure 7. A slight increase in the rates of gas formation of the various products is observed. In light of the fact that we are assuming that the decomposition of 2,4-DNI in the reactive shell is undergoing a unimolecular decomposition in the model, it is reasonable to assume that the rate constant for 2,4-DNI in the gas phase would be similar. Given these assumptions, comparing the results of the two calculations to the data, and realizing that the relative contributions of decomposition in the shell and decomposition in the gas phase are proportional to the amount of 2,4-DNI available to react in each process, it appears that our estimation of the amount of material available for reaction in the shell is approximately correct. For example, if we assumed that the thickness of the reactive shell was $1 \mathrm{~nm}$ instead of $10 \mathrm{~nm}$, then the contribution from gas-phase reactions in the larger cell would have been ten times larger and running the experiment in the larger volume reaction cell would have had significantly different results from our basis experiment. On the other hand, if we assumed the thickness of the reactive shell was $100 \mathrm{~nm}$, then the contribution of gas-phase reactions would be even less. Given the differences between the calculated rates from the model and the data, when the gas-phase rate constant is set to zero, it is difficult to determine whether the slightly better fits to several of the gas evolution rates when the gas-phase rate constant is set equal to ks is actually due to the gas phase contributions or some other aspect of the decomposition process. Thus, the certainty for an estimated value of the maximum thickness of the reactive shell is low. 
Presented at the 34th JANNAF Combustion Subcommittee Meeting

West Palm Beach, Florida, October, 1997

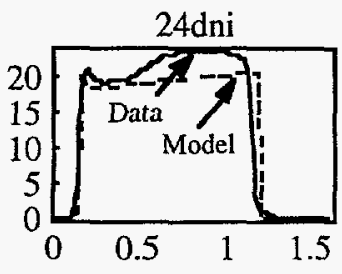

\section{Experimental Parameters:}

Orifice diameter $(\mu \mathrm{m}): 25$.

Isothermal temp (C): 237.5

Reaction cell volume (cm3): 0.199

Sample weight $(\mathrm{mg}): 10.32+1.7$ residue

Average particle dia $(\mu \mathrm{m}):-10$. (est.)
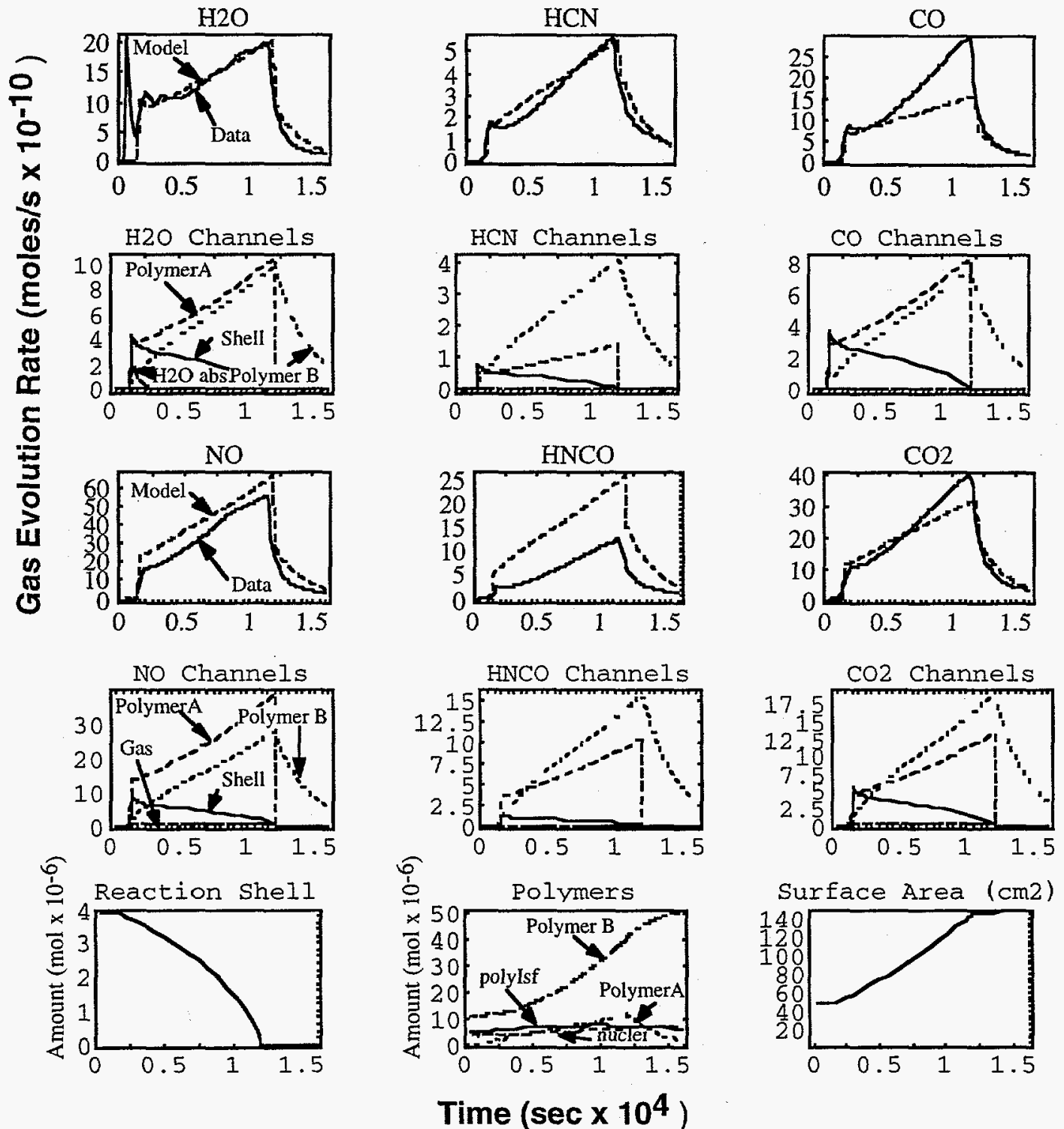

\section{Time (sec $\left.\times 10^{4}\right)$}

Figure 6. The evolution rates of gaseous products, resulting from the decomposition of 2,4-DNI mixed with a residue from a previous experiment, are shown along with the results from a model of the decomposition process. Plots with only product labels show the measured rate of gas evolution from the reaction cell (solid line) and the resulting fit of the model (dashed line) for each product. Plots of the product channels show the contribution of each channel described in the model to the overall evolution of each decomposition product. The legend for each type of plot is shown in the first plot in each row. 


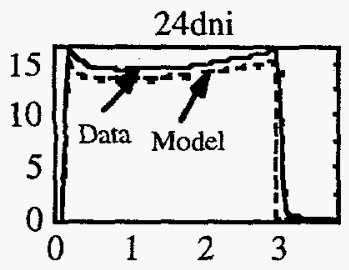

\section{Experimental Parameters:}

Orifice diameter $(\mu \mathrm{m}): 25$.

Isothermal temp (C): 235.4

Reaction cell volume $\left(\mathrm{cm}^{3}\right): 1.46$

Sample weight (mg): 9.55

Average particle dia $(\mu \mathrm{m}): \sim 10$. (est.)
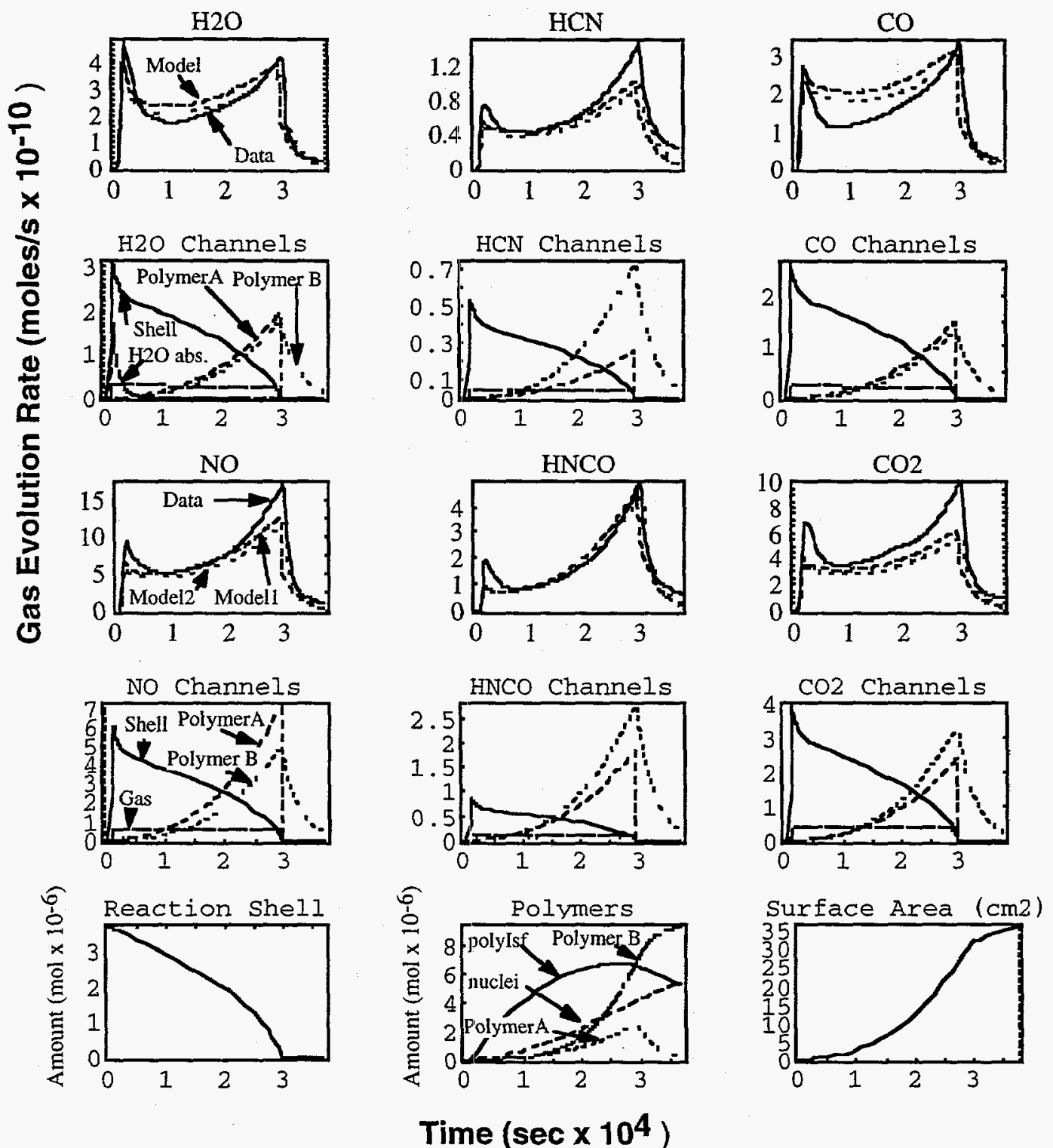

Figure 7. The evolution rates of gaseous products from the decomposition of 2,4-DNI in a larger volume reaction cell $\left(1.46 \mathrm{~cm}^{3}\right)$ is shown along with the results from a model of the decomposition process. Plots with only product labels show the measured rate of gas evolution from the reaction cell (solid line) and the results of two different calculations with the model. One calculation with the model includes no contributions from gas-phase reactions (short dashes) while the other calculation does include gas-phase contributions (long dash). Plots of the product channels show the contribution of each channel described in the model to the overall evolution of each decomposition product. The legend for each type of plot is shown on the first plot in each row. 
Temperature dependence. The temperature dependence of the processes is incorporated into the model by optimizing the rate constants to fit the data collected in experiments at several different isothermal temperatures. An example of a fit to one set of data collected in an experiment at $244.3^{\circ} \mathrm{C}$ is shown in Figure 8 . The four rate constants, ks, knuc, $\mathrm{kr}$ and $\mathrm{kpd}$, were the only parameters adjusted to fit the data. The stoichiometric coefficients and all other parameters are the same as those used in fitting the basis experiment. The procedure for optimizing the coefficients by comparison to the data is the same method used for the basis experiment.

The results of the optimization procedure show the rate constants have been optimized to correctly predict the depletion time of the sample, and thus, the correct amount of 2,4-DNI decomposed. A comparison of the measured gas evolution rates with corresponding calculated rates from the model are for the most part in good agreement. However, close inspection shows that there are several differences. For example the model predicts higher gas evolution rates for $\mathrm{NO}$ and $\mathrm{H}_{2} \mathrm{O}$, in the final stages of the decomposition, than actually measured. The model also predicts a lower rate of $\mathrm{CO}_{2}$ evolution than measured. We suspect these deviations arise from our oversimplification of the global reaction chemistry used for each process. These deviations will be used to create a more accurate representation of the reaction chemistry in the next generation of the model.

Comparison of the relative contributions to the gas evolution rates of the individual species from each decomposition process shows that in the higher temperature experiment more of the products are formed from reaction between the 2,4-DNI and the polymer than from decomposition in the reactive shell.

Extent of decomposition. For the experiments discussed to this point, the ratio of the undecomposed 2,4-DNI to the decomposed 2,4-DNI has ranged from 0.45 for reaction with residue from a previous experiment, to 0.8 for decomposition at $244^{\circ} \mathrm{C}$, up to 1.8 to 2.0 for experiments at $235^{\circ} \mathrm{C}$ in the standard and large volume reaction cells. In the results from the experiment presented in Figure 9, the orifice diameter used in the reaction cell for the experiment was increased from $25 \mu \mathrm{m}$ to $50 \mu \mathrm{m}$. The ratio of undecomposed to decomposed 2,4-DNI in this experiment was 12.5. Thus, only one out of twelve 2,4-DNI molecules underwent decomposition.

The results differ quite dramatically from the previous experiments, in which a larger fraction of the sample decomposed. The two most notable differences are the lack of a significant contribution from reaction between the 2,4-DNI and the polymer, and the larger increase in the rates of gas evolution due to the exogenous water absorbed in the sample. The larger rates of gas evolution due to exogenous water are most likely due to slightly different conditions used for this experiment. In this experiment the $2,4-\mathrm{DNI}$ was held at $-121^{\circ} \mathrm{C}$ for 10,000 seconds whereas in the previous experiments it was held at $200^{\circ} \mathrm{C}$ for 15,000 seconds. This suggests that this experiment contained more exogenous water when it reached $235^{\circ} \mathrm{C}$, increasing the reaction rates to higher levels during the early stages of the reaction compared to the basis experiment.

The more interesting difference is in the limited extent of contribution of the autocatalytic process between 2,4DNI and the polymer. This is consistent with the model for two reasons. First, the rate of formation of the critical size nuclei are dependent on the concentration of 2,4-DNI in the volume of the reactive shell. The lower concentration leads to a lower rate of formation of critical size nuclei. Second, since the exhaust rate of 2,4-DNI from the reaction cell is greater, the sample is depleted in a shorter period of time and the process involving the growth of the polymer is shortened.

The most significant difference between the measured data and the calculated rates is in the values for the NO gas evolution rate. The measured rate of NO evolution is 3 times greater than the rate predicted by the model. This discrepancy suggests that either the decomposition mechanism of 2,4-DNI is significantly different at lower extents of decomposition or that there is a possible error in the experiment. These issues are being considered in the next generation of the model. 


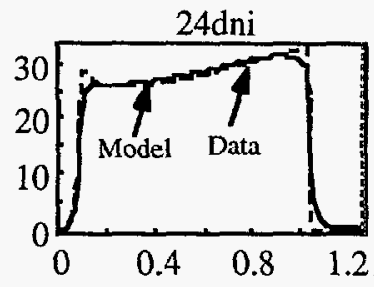

\section{Experimental Parameters:}

Orifice diameter $(\mu \mathrm{m}): 25$.

Isothermal temp (C): 244.3

Reaction cell volume (cm3): 0.199

Sample weight $(\mathrm{mg}): 10.32$

Average particle dia $(\mu \mathrm{m}): \sim 10$. (est.)
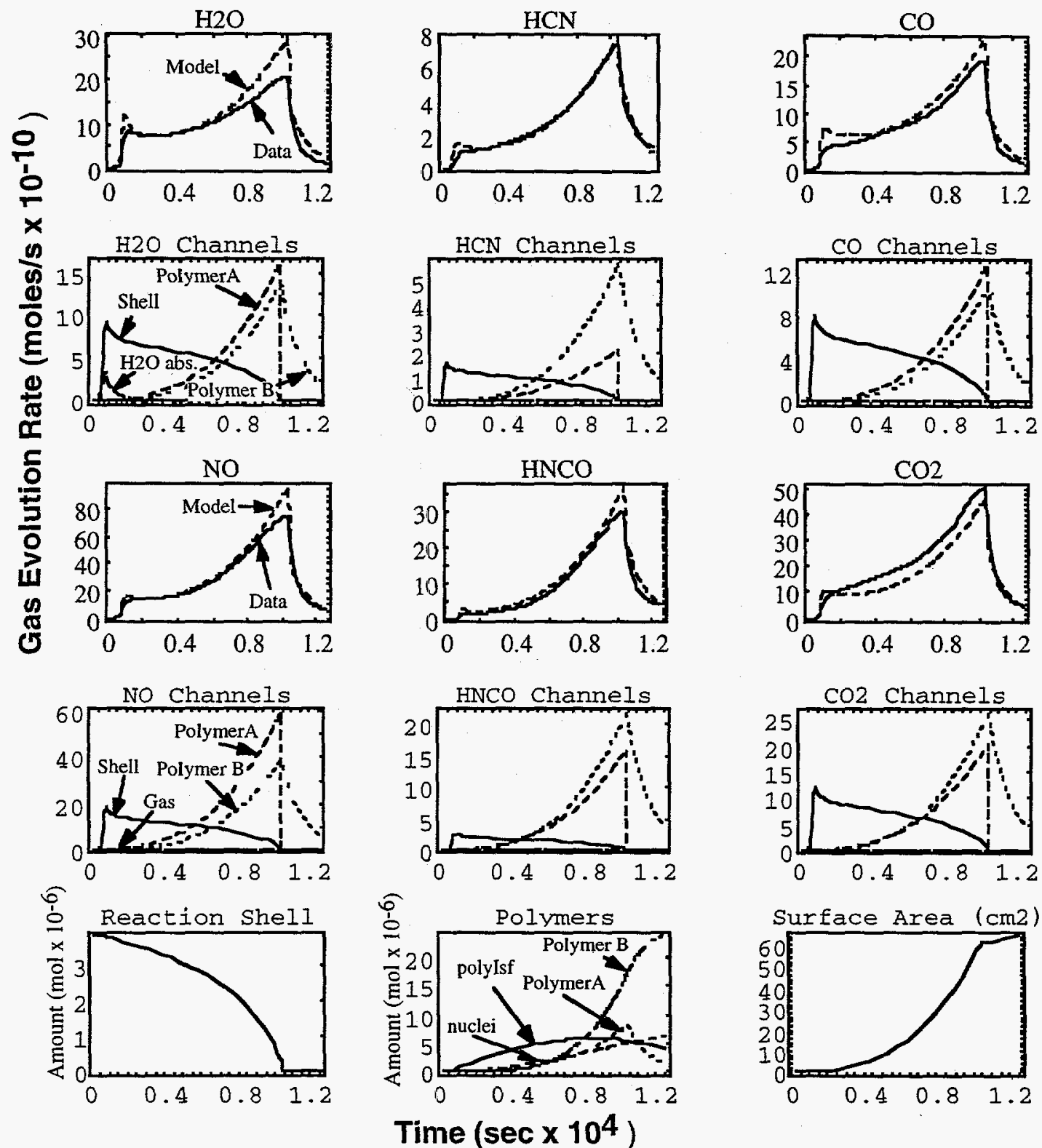

Figure 8. The evolution rates of gaseous products from the decomposition of 2,4-DNI at a higher temperature $\left(244^{\circ} \mathrm{C}\right)$ are shown along with the results from a model of the decomposition process. Plots with only product labels show the measured rate of gas evolution from the reaction cell (solid line) and the resulting fit of the model (dashed line) for each product. Plots of the product channels show the contribution of each channel described in the model to the overall evolution of each decomposition product. The legend for each type of plot is shown on the first plot in each row. 


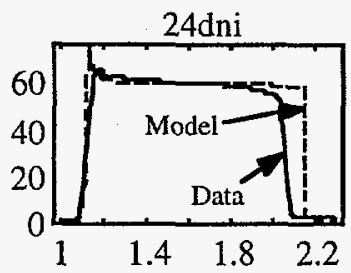

\section{Experimental Parameters: \\ Orifice diameter $(\mu \mathrm{m}): 50$. Isothermal temp (C): 236.}

Reaction cell volume $\left(\mathrm{cm}^{3}\right): 0.199$

Sample weight $(\mathrm{mg}): 10.4$

Average particle dia $(\mu \mathrm{m}): \sim 10$. (est.)
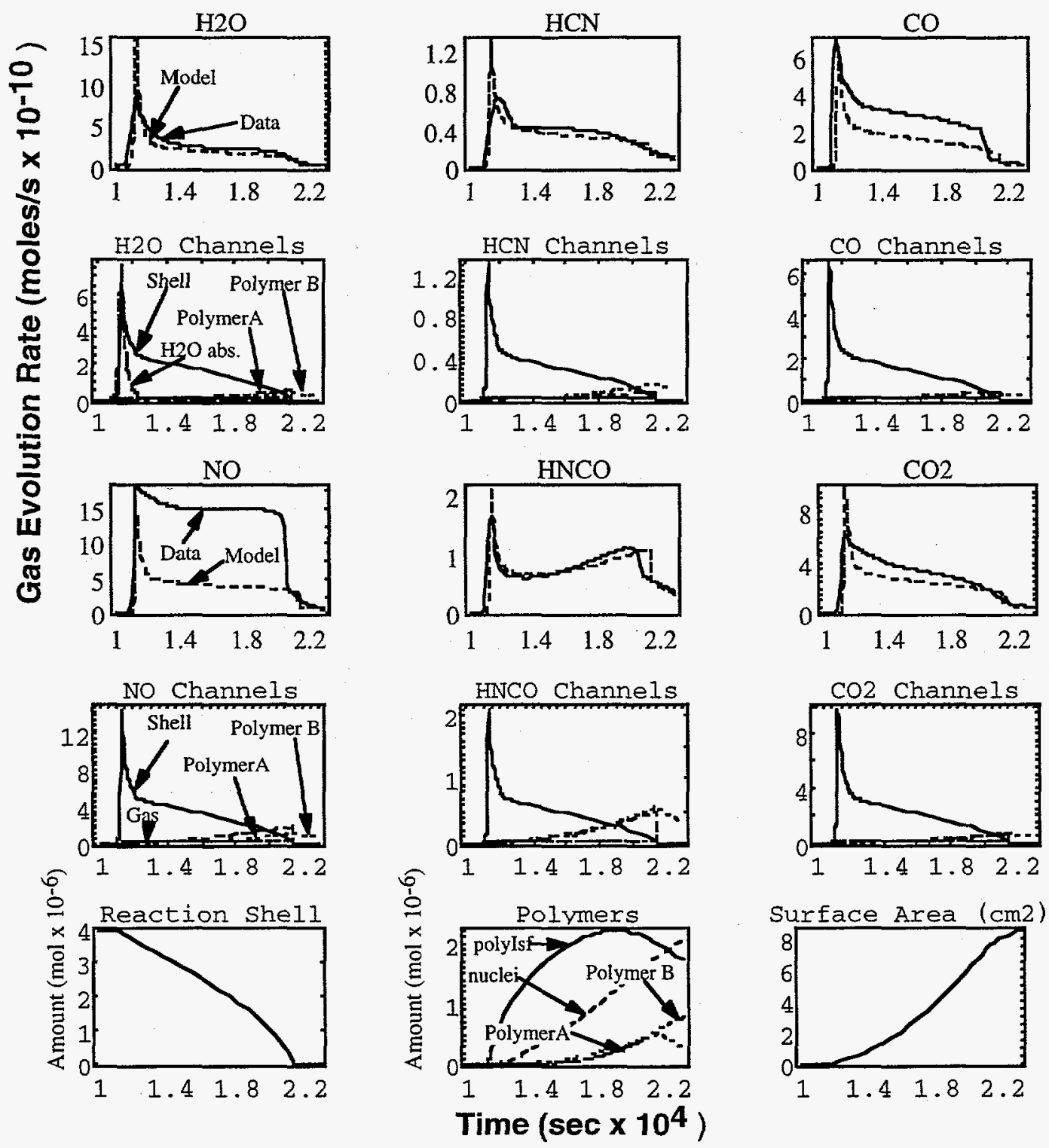

Time $\left(\sec \times 10^{4}\right)$

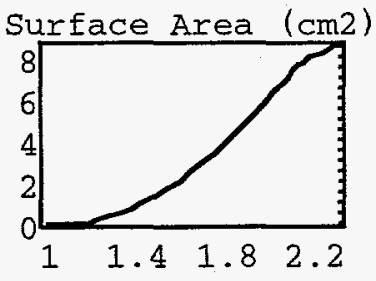

Figure 9. The evolution rates of gaseous products from the decomposition of 2,4-DNI using a larger diameter orifice $(50 \mu \mathrm{m})$ are shown along with the results from a model of the decomposition process. Plots with only product labels show the measured rate of gas evolution from the reaction cell (solid line) and the resulting fit of the model (dashed line) for each product. Plots of the product channels show the contribution of each channel described in the model to the overall evolution of each decomposition product. The legend for each type of plot is shown on the first plot in each row. 
Presented at the 34th JANNAF Combustion Subcommittee Meeting

West Palm Beach, Florida, October, 1997

Outstanding issues. The following outstanding issues are being addressed in the next generation of the reaction model:

1. The details of the reaction chemistry will be developed. New reactions will be formulated from differences between the gas evolution rates for the various products predicted by the model, and the measured data collected in experiments spanning the temperature range of the process $\left(200^{\circ} \mathrm{C}\right.$ to $\left.255^{\circ} \mathrm{C}\right)$.

2. Information derived from results of infrared, microscopic, and mass spectrometric analysis of the residue will be incorporated into the model.

3. Better characterization of the sample morphology will be made.

4. The effects of containment of gaseous products and the extent of reaction will be evaluated using results from experiments conducted using smaller diameter reaction cell orifices.

5. The effects of sample size will be evaluated.

\section{SUMMARY}

Our study of the solid-phase thermal decomposition behavior of 2,4-DNI has shown that the decomposition behavior is complex, and not defined by a single dominant process that can be accurately represented with a simple analysis of the quantified results. The decomposition products consist of several different gases and a polymeric residue that accounts for $-40 \%$ of the total decomposition product weight. A first-generation model has been developed to describe the solid-phase pyrolysis of 2,4-DNI, that is based on the temporal behaviors of the gasevolution rates of the gaseous products of decomposing 2,4-DNI under various conditions. The results of the model show that the decomposition of 2,4-DNI and evolution of gaseous products is controlled by at least six basic processes. These processes include: 1) sublimation and decomposition in the gas phase (small contribution), 2) decomposition in a reactive shell on the surface of the particles, 3) enhancement of the reaction rates and reduction of the 2,4-DNI sticking coefficient due to absorbed exogenous water and impurities in the 2,4-DNI sample, 4) the growth of polymeric reactive nuclei in the reactive shell, 5) adsorption of 2,4-DNI on the surface of the reactive nuclei, followed by reaction of the 2,4-DNI on the surface to release gaseous products and add to the polymer, and 6) transformation of the polymer formed by the initial reaction with 2,4-DNI to a more thermally stable polymer, releasing gas in the process. The combination of processes four through six characterize the autocatalytic nature of the 2,4-DNI decomposition. . Global reaction chemistry has been used to characterize each of the basic decomposition processes in the first generation of the model. At the model's present state of development, global chemistry is used to represent the various chemical reactions that occur during each of the processes just described. Differences between the rates of gas formation predicted by the model and the measured data will be used to generate a second-generation model of the 2,4-DNI decomposition processes that include more details on the individual chemical reactions involved in each process.

\section{ACKNOWLEDGMENTS}

The authors thank Mr. D.M. Puckett for collecting the mass spectrometry data and to Dr. Phil Pagoria for providing the 2,4-DNI sample. Work is supported by the Army Research Office, a Memorandum of Understanding between the DoD Office of Munitions and the Department of Energy under Contract DE-AC04-94AL85000, and by the U.S. Army, ARDEC.

\section{REFERENCES}

1 R. Behrens, Jr., Journal of Physical Chemistry 94, 6706-6718 (1990).

2 R. Behrens, Jr. and S. Bulusu, Journal of Physical Chemistry 95, 5838-5845 (1991).

3 S. Bulusu and R. Behrens, Defence Science Journal (India) 46, 347 - 360 (1996).

4 R. Behrens, Jr. and S. Bulusu, Journal of Physical Chemistry 96, 8877-8891 (1992).

5 R. Behrens, Jr. and S. Bulusu, Journal of Physical Chemistry 96, 8891-8897 (1992).

6 R. Behrens, Jr., T. A. Land, and S. Bulusu, in 30th JANNAF Combustion Meeting (Chemical Propulsion Information Agency, Monterey, California, 1993). 
7 R. Behrens and S. Bulusu, in 32nd JANNAF Combustion Subcommittee Meeting (CPIA Publication \#638, Huntsville, AL, 1995), Vol. 1, p. 1 - 11.

8 R. Behrens, Jr. and S. Bulusu, in Fall 1992 Meeting of the Materials Research Society, edited by R. W. Armstrong, J. J. Gilman and D. H. Liebenberg (Material Research Society, Boston, Mass., 1992), Vol. 296, p. $13-24$.

9 S. Bulusu, R. Damavarapu, J. R. Autera, et al., Journal of Physical Chemistry 99, 5009-5015 (1995).

10 L. Minier, R. Behrens, and S. Bulusu, in 1995 JANNAF 32nd Combustion Subcommittee (CPIA, Huntsville, Alabama, 1995).

11 L. Minier, R. Behrens, and T. J. Burkey, in 33rd JANNAF Combustion Meeting (CPIA Publication \# 653, Monterey, CA, 1996), Vol. 2, p. 427 - 437.

12 R. Behrens and L. Minier, in 33rd JANNAF Combustion Meeting (CPIA Publicaton \# 653, Monterey, CA, 1996), Vol. 2, p. 1-19.

13 K. Jayasuriya, R. Damavarapu, R. L. Simpson, et al., (Lawrence Livermore National Laboratory, 1993).

14 R. L. Simpson, C. L. Coon, M. F. Foltz, et al., (Lawrence Livermore National Laboratory, 1993).

15 R. Behrens, Jr., Reveiw of Scientific Instruments 58, 451 (1986).

16 R. Behrens, Jr., International Journal of Chemical Kinetics 22, 135-157 (1990).

17 R. Behrens, Jr., International Journal of Chemical Kinetics 22, 159 (1990).

18 L. Minier, R. Behrens, and S. Bulusu, in Decomposition, Combustion and Detonation Chemistry of Energetic Materials, edited by T. B. Brill, T. P. Russel, W. C. Tao and R. B. Wardle (Material Research Society, Boston, MA, 1996), Vol. 418, p. 111 - 117. 